\title{
Hacia una noción de interpretación en la ciencia: anotaciones críticas al planteamiento de N. R. Hanson
}

Towards a Notion of Interpretation in Science: Critical Remarks on N. R. Hanson's Approach

\author{
Mónica Magaña JatTar y Julio Horta \\ Instituto de Investigaciones Filosóficas / \\ Facultad de Ciencias Políticas y Sociales \\ Universidad Nacional Autónoma de México
}

\begin{abstract}
RESUMEN: El presente trabajo hace una revisión crítica de la propuesta filosófica de Norwood R. Hanson con el objetivo de exponer los límites de su planteamiento teórico sobre la interpretación en la ciencia. La primera parte del trabajo expondrá el proyecto hansoniano, buscando evidenciar sus contribuciones frente a la filosofía de la ciencia y al pensamiento científico, mientras que en los dos apartados siguientes se realizará una crítica a su postura filosófica. Dicha crítica se realizará a partir de dos ejercicios de reflexión filosófica, que constituyen dos momentos complementarios de análisis. Por un lado, a nivel de análisis metodológico, se mostrará que las "figuras de perspectivas reversibles" utilizadas como argumentos para explicar su propuesta filosófica son insuficientes en la descripción del proceso de interpretación; por el otro, a nivel teórico, se cuestionará su noción de lenguaje y las categorías implicadas en este concepto para mostrar que la propuesta teórica "visióninterpretación" de Hanson tiene como fundamento nociones epistemológicas y analíticas. Desde esta perspectiva, se mostrará que el planteamiento "hermenéutico-interpretativo" de Hanson resulta incompleto, pues no llega a desarrollarse hacia una ontología del lenguaje.
\end{abstract}

ABSTRACT: In the present work we have made a critical review of the philosophical proposal of Norwood R. Hanson with the aim of exposing the limits of its theoretical approach on the problem of interpretation in science. The first part of this work exposes the hansonian project, looking for evidence of his contributions to the philosophy of science and scientific thinking. In the following two sections we present a critique to his philosophical proposal. We present two exercises of philosophical reflection that constitute two complementary moments of analysis. On one hand, at the level of methodological analysis, we present a discussion about how the "reversible perspective figures" that have been used for the author as arguments to explain his philosophical proposal, are insufficient to the description of the process of observation and interpretation. On the other hand, at the theoretical level, we question his notion of language and categories to show that his theoretical proposed "vision-interpretation" has based on epistemological and analytic notions. From this perspective, it will be shown that the "hermeneutical-interpretative" approach of Hanson is incomplete, since it does not develop towards an ontology of language and observation.

PALABRAS CLAVE: interpretación, ontología, epistemología, imágenes reversibles, lenguaje, representación.

KEYWORDS: observation, interpretation, ontology, epistemology, reversible perspective, language, representation.

RECIBIDO: 17 de abril de 2015 - ACEPTADO: 22 de junio de 2015 


\author{
Mónica Magaña JatTar y Julio Horta \\ Instituto de Investigaciones Filosóficas / \\ Facultad de Ciencias Políticas y Sociales, \\ Universidad Nacional Autónoma de México
}

\title{
Hacia una noción de interpretación en la ciencia: anotaciones críticas al planteamiento de N. R. Hanson ${ }^{1}$
}

\section{Introducción}

En la relación entre experiencia y percepción del sujeto en el proceso del conocimiento, un problema fundamental consiste en considerar, por un lado, la correspondencia del conocimiento con algún objeto de la experiencia y, por otro, el carácter general y la naturaleza misma del conocimiento subjetivo. Desde una postura fenomenológica queda claro que el sujeto no puede tener acceso al objeto de la experiencia más que por la mediación de una estructura a priori, a través de la cual determina los datos sensibles. La estructura del sujeto es condición necesaria para que la experiencia se realice como experiencia subjetiva, como una representación que potencialmente puede ser entendida e interpretada por otros sujetos.

Norwood Russell Hanson busca dar cuenta de las relaciones que existen entre la observación y la experiencia, para, mediante el análisis de

\footnotetext{
Las reflexiones en este artículo tienen su origen en el seminario "Hermenéutica y filosofía de la ciencia”, impartido por la Dra. Maricruz Galván, que se llevó a cabo en el Posgrado de Filosofía de la Ciencia del Instituto del Investigaciones Filosóficas (UNAM), de agosto a diciembre de 2012. Al respecto, agradecemos los comentarios y la revisión crítica por parte de la Dra. Galván; sin duda este ensayo se enriqueció con sus aportaciones así como con la dinámica desarrollada durante el seminario.
} 
los diferentes componentes que conforman la visión, fundamentar la relación específica entre visión e interpretación. En este sentido, afirma que la interpretación es un elemento intrínseco de la visión. Con base en esto sostiene una postura trascendental (de carácter kantiano), pues la visión no es un estado físico propio de las cosas y objetos ni un estado fisiológico, sino una experiencia en la cual lo sensible se organiza a través de "estructuras" que la conciencia subjetiva pone.

Este planteamiento filosófico tiene importantes implicaciones en el modo de considerar el conocimiento generado por las ciencias empíricas (tanto sociales como naturales), a saber, vulnera la posición científica que se fundamenta en las posturas positivistas del conocimiento objetivo y el criterio de verdad por correspondencia. Sin embargo, pese a que Hanson introduce el vínculo entre interpretación y observación como un cuestionamiento hacia la corriente positivista en la filosofía de la ciencia, su posición teórico-metodológica no alcanza a desarrollarse como una alternativa que abra nuevas posibilidades hacia la consideración de una hermenéutica en las ciencias empíricas.

En efecto, la hermenéutica es una disciplina que puede adecuarse al estudio de las representaciones, signos y lenguajes, pues tiene como fin la comprensión de las manifestaciones culturales, sociales e históricas que dan sentido a los diferentes sistemas de lenguaje. De ahí que tanto las "ciencias de la naturaleza" como las "ciencias del espíritu" (Dilthey 1986: 45 y ss.), en tanto que están conformadas por sistemas de lenguajes elaborados por y para sujetos sociales, son susceptibles del estudio hermenéutico. ${ }^{2}$

El presente trabajo busca hacer una revisión crítica de la propuesta filosófica de Hanson, con la intención de exponer los límites de su planteamiento con respecto a la complejidad interpretativa implicada en el estudio de los fenómenos. Primero se expondrá de manera concreta el proyecto hansoniano, buscando evidenciar sus contribuciones frente a la filosofía de la ciencia positivista y al pensamiento científico.

2 Por referir la oposición establecida por W. Dilthey. Esta distinción tiene como fundamento la diferencia en la naturaleza misma del objeto de estudio en cada ámbito: en las ciencias de la naturaleza su objeto de estudio es un "objeto", que puede ser determinable y generar así conocimiento, mientras que en las ciencias del espíritu se estudian "sujetos", con lo cual se implica no sólo un conocimiento, sino el reconocimiento de lo propio en el otro (autoconocimiento, autoconciencia) en la temporalidad de la "vivencia". 
Ahora bien, la crítica a este planteamiento filosófico se realizará a partir de dos ejercicios de reflexión filosófica. Cabe aclarar al lector que ambos ejercicios, dentro de sus propias dinámicas discursivas (que en principio pueden parecer diferentes), constituyen dos momentos de análisis que son complementarios. Así pues, por un lado, a nivel de análisis metodológico, se mostrará que las figuras de perspectivas reversibles utilizadas como argumentos en la propuesta filosófica de Hanson son insuficientes en la descripción del proceso de interpretación. Por otro lado, a nivel teórico, se cuestionará la noción de "lenguaje" de Hanson y las categorías implicadas en este concepto para mostrar que el planteamiento tiene como fundamento nociones epistemológicas y semiótico-analíticas. Desde este punto, su potencial planteamiento "hermenéutico-interpretativo" resulta incompleto porque no llega a desarrollarse hacia una ontología del lenguaje. ${ }^{3}$

\section{El concepto "carga teórica” y la relación visión-interpretación}

El problema es claro: si dos observadores ven un mismo objeto, pero parten de teorías diferentes, ¿realmente ven lo mismo? Suponer que ambos sujetos ven la misma cosa pero la interpretan de manera diferente, puede ser una solución engañosa, ya que de inicio considera que la percepción del objeto está separada de su consecuente interpretación. Para Hanson, la cuestión está en "mostrar cómo estos datos (sensoriales) son moldeados por diferentes teorías o interpretaciones o construcciones intelectuales" (2010: 218).

En esta dirección, resulta necesario hacer un análisis acerca de los conceptos de visión-observación y, siguiendo al autor, considerarlos como elementos que constituyen la estructura conceptual del sujeto. La imagen generada por efecto de la visión es una representación mental

3 El texto por discutir, "Observación", corresponde al primer capítulo del libro de Hanson (2010). Las reflexiones aquí vertidas se refieren a los contenidos y propuestas del texto referido, y no propiamente al trabajo completo de Hanson en su libro. Se buscará evidenciar el valor epistemológico de la propuesta hansoniana, pero situando sus aportaciones filosóficas dentro de un contexto reflexivo más amplio. 
y no sólo el resultado de un estado físico. Si la visión estuviera constituida sólo por el ojo y las reacciones que ocurren en la retina, entonces habría algo así como una visión (una y única), independiente de los sujetos que ordenan los datos sensoriales. Según Hanson, esto último no puede sostenerse en la experiencia de cada sujeto.

Siguiendo la filosofía kantiana, la tesis de Hanson arroja una definición: "la visión es una experiencia". En términos de la filosofía trascendental, una experiencia en sentido fuerte es sólo posible cuando el material de la experiencia es determinado por los conceptos y categorías del sujeto. Asumir esta postura, pero leída en clave de Hanson, permite considerar la visión como una experiencia en sentido kantiano, donde la visión y lo visto están constituidos por conceptos previos con los cuales se determina e interpreta la experiencia. En este sentido, la experiencia sólo es posible por el "conocimiento previo".

Este conocimiento inherente a la visión es denominado por Hanson "carga teórica", esto es, la visión es una acción que lleva consigo un conocimiento. La "organización" de los datos sensoriales no está en los elementos que constituyen el objeto percibido - la organización no es un elemento que exista en el campo visual - , sino que la organización subjetiva funciona como un "argumento" que configura y "estructura" los datos sensibles. De ahí la línea kantiana de este filósofo: el sujeto está condicionado por un conocimiento previo para apreciar sólo ciertos aspectos perceptibles. En este análisis se acepta que si bien la interpretación permite inferir cualidades y atributos de los objetos por medio de un lenguaje, no obstante interpretación e inferencia dependen de un contexto verbal.

Aunque Hanson reconoce que la visión no es algo compuesto, sí acepta dos momentos a priori del ver. Por un lado, reconoce un momento denominado "ver como" que, en tanto ver de aprehensión, se refiere a la percepción de las cualidades o características de los objetos, y por otro, el "ver qué", que constituye un ver de conocimiento a través del lenguaje. Esta última forma del ver permite saber qué clase de cosas se pueden denotar: ver un objeto en razón de un conocimiento previo. ${ }^{4}$

4 Hanson refiere como argumento una cita de Wisdom que resulta pertinente. Para Wisdom "cada percepción implica una etiología y una prognosis" (citado en Hanson 2010: 242). Como la visión está en relación con un conocimiento previo, entonces la percepción misma conlleva un sistema de causas (una explicación del porqué) y un 
Así, "ver qué" inserta un saber en la visión y con ello impide "reidentificar" cada objeto que se presenta ante el sujeto en la experiencia. De suerte que Hanson afirma que "ver un objeto X, es ver que este objeto puede comportarse según sabemos que se comportan los objetos X; si el comportamiento del objeto no concuerda con lo que esperamos de un $\mathrm{X}$, nos veremos obligados a no verlo, en adelante, como un X" (Hanson 2010: 242).

La propuesta del autor afirma categóricamente que "la interpretación es la visión”. El conocimiento está en la visión, y es en razón de un conocimiento previo que el sujeto interpreta. Resulta entonces que la interpretación está en la visión misma. Ambos, visión e interpretación, son parte de un mismo proceso en donde se vinculan imágenes y oraciones para configurar la experiencia calculada (no azarosa) denominada "observación".

Sobre las imágenes de perspectivas reversibles ${ }^{5}$

Hanson utilizó las figuras de perspectivas reversibles como parte de un recurso metodológico en pro de advertir sobre el pluralismo ontoepistemológico de la observación. Las figuras de perspectivas reversibles pueden entenderse como aquellas que, dado su diseño, evocan intencionalmente un mínimo de dos figuras distintas "dentro del mismo elemento", lo cual permite interpretarlas (observarlas) de diferentes maneras. Cuestionar las imágenes respecto a cómo son, por qué y cuál es su función dentro del texto, nos permitió notar problemáticas y debilidades que merman la fortaleza misma del planteamiento original.

Si aceptamos que se ve porque se interpreta y se interpreta por y con la carga teórica, la visión es interpretación, y ambos constituyen un mismo momento. Lo que es significativo tiene determinación relativa al peso que cada individuo o grupo social, con su espacio-tiempo, le den a una cuestión en particular, sin importar que se trate de un "objeto común con características propias". Pero, ¿cómo es que el caso de las

conocimiento anticipado (una expectativa previa).

5 En este apartado se mostrarán algunas de las imágenes utilizadas por el autor en el capítulo ya referido. 
figuras de perspectivas reversibles, como recurso metodológico, debilita la propuesta? Veamos lo siguiente:

Las figuras de perspectivas reversibles son ejemplos de las diferentes cosas que se ven en la misma configuración, donde esta diferencia no se debe a imágenes visuales diferentes ni a "interpretaciones" superpuestas a la sensación. [...] Algunos verán en la figura [...] una anciana parisiense, otros una joven (a la Toulousse-Lautrec). Todas las retinas normales "reciben" la misma imagen, y nuestras imágenes de datos sensoriales deben ser las mismas, puesto que, si usted ve una anciana y yo una joven, las imágenes que dibujemos de lo que vemos pueden llegar a ser geométricamente indistinguibles (Hanson 2010: 227-228) (figura 1).

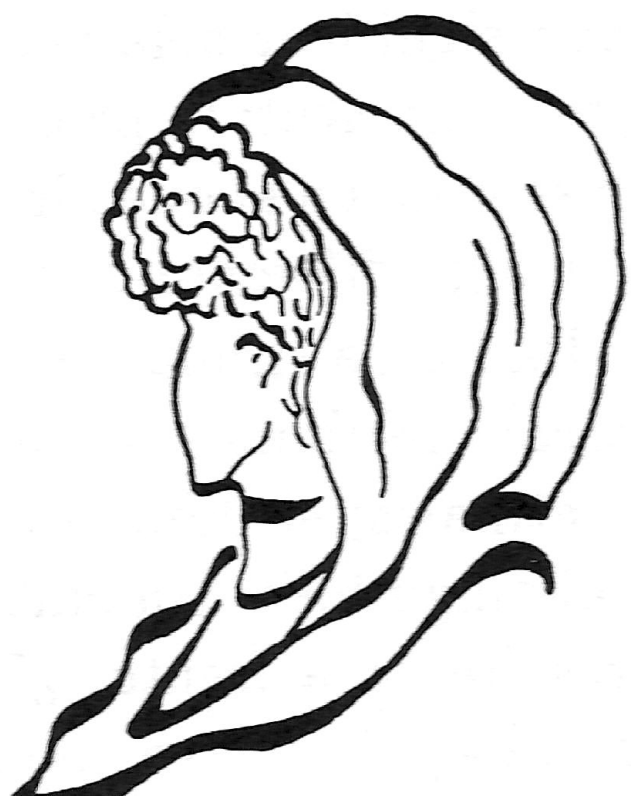

Figura 1.

Resaltemos algunos puntos interesantes: 1) ¿puede hablarse de una misma configuración cuando ésta ha sido diseñada con la intención de ser a la vez dos o más configuraciones distintas? Decir que la diferencia interpretativa no se debe a imágenes visuales diferentes ni a interpretaciones superpuestas a la sensación, afirma y niega la pluralidad interpretativa de la observación cuando este tipo de figuras favorecen, pre- 
cisamente, interpretaciones superpuestas artificialmente. 2) Si usted ve a una "anciana" y yo a una "joven", y si las imágenes que dibujáramos de éstas pueden ser geométricamente iguales, $a$ ) ¿se asume una verdad por correspondencia?, b) ¿se mantiene la separación sujeto-objeto?, $c$ ) al asumir que observamos a una "joven” o a una "anciana”, ¿se enarbola el conocimiento necesario?

La visión es una experiencia. Una reacción de la retina es solamente un estado físico, una excitación fotoquímica. [...] Son las personas las que ven, no sus ojos. Las cámaras fotográficas y los globos del ojo son ciegos. Pueden rechazarse los intentos de localizar en los órganos de la vista [...] algo que pueda denominarse visión (Hanson 2010: 220-221).

La carga teórica determina lo que observamos debido a que la experiencia de nuestra vida se impone en el momento preciso en el que la efectuamos, siendo la primera parte constitutiva de una condición de posibilidad, mas no una determinación inamovible frente a sus condicionamientos históricos. Frente a otros ejemplos del mundo que tomáramos como objetos de la experiencia, cualquier diseño artificial anula la advertencia de la pluralidad ontoepistemológica de la observación.

Las figuras de perspectivas reversibles representan un todo delimitado que implica un constreñimiento ontoepistemológico; no obstante, la pluralidad de la observación existe, ¿entonces? Nótese que al afirmar que "la pluralidad existe", no nos estamos saliendo del argumento hansoniano; con las figuras de perspectivas reversibles, sí:

Algunos filósofos tienen una fórmula dispuesta para estas ocasiones: "Naturalmente, ellos ven la misma cosa. Hacen la misma observación, puesto que parten de los mismos datos visuales. Pero lo que ven lo interpretan de una forma diferente". La cuestión es, entonces, mostrar cómo estos datos son moldeados por diferentes teorías o interpretaciones o construcciones intelectuales (Hanson 2010: 217-218).

Si la cuestión es mostrar cómo los datos son moldeados por las diferentes teorías, interpretaciones o construcciones intelectuales, las figuras de perspectivas reversibles no son un elemento "neutral" que permita mostrar cómo los datos previos pueden ser tan variables como 
personas existentes, y con éstos, el moldeado de las observaciones posibles, y aún con ello, ser éstas tan dispares como impredecibles.

Poner a prueba la pluralidad ontoepistemológica de la observación a través de las figuras de perspectivas reversibles conlleva asumir: a) una estructura del sujeto que puede ordenar los datos de la experiencia sensible de una forma predecible y limitada, $b$ ) que el objeto está fuera del sujeto y que, por tanto, c) accede sin afecciones a una suerte de realidad objetiva que puede interpretarse y describirse, lo que, además, conduce al conocimiento necesario: a la relación unívoca y recíproca entre sujeto y objeto.

Pero, ¿qué sucede si el "ordenamiento" de los datos sensibles no encaja según los “condicionamientos teóricos”? Es decir, ¿por qué cuando se ve la imagen de joven/anciana, pato/conejo o pájaro/antílope, y en general cualquier figura de perspectiva reversible, "no puede" observarse cualquier otra cosa?

La respuesta apunta a lo que se ha tratado de advertir: la figura, en sí, es antipluralista, en el sentido ontoepistemológico, toda vez que es realista, pues no permite observar lo que de hecho no está ahí. Estas figuras y las de su tipo están diseñadas para evocar elementos que se cree que son reales para el observador, y resulta poco probable que haya algo en el mundo que esté diseñado para ser una cosa y no la otra, o que exista un objeto en el mundo que al ser observado o interpretado, resulte en un solo par de interpretaciones y teorías explicativas. De hecho, no se puede negar la posibilidad de que aun dentro de un contexto común y durante la lectura de este texto, el lector nunca observe nada de lo que se está refiriendo. Esto es muy interesante.

La "realidad" y la relación que los individuos tenemos con ella no son un diseño o una circunstancia estática; al contrario, no parece estar hecha ad hoc a nuestras "posibles y ordenadas interpretaciones". Uno de los grandes aportes de la hermenéutica ha sido advertir que no existe un todo aislado y estático, sino un todo en el todo y por el todo que nunca deja de moverse y afectarse recíprocamente, lo que implica una realidad "verdadera" amén de su impermanencia y afectación constante con el todo y en el todo. El diseño, por definición, es estático e inamovible. Aunque algunos lectores podrían considerar que una imagen puede representar un mundo, es decir, “el mundo de la imagen”, ¿cómo 
concebir un mundo sin movimiento ni posibilidades, diseñado, ahí, listo para una interpretación inmediata?

Las figuras que utiliza Hanson, al estar diseñadas para que comprendan imágenes visuales diferentes e interpretaciones superpuestas a la sensación (válidas sólo en un marco conceptual más o menos compartido), suponen una realidad objetiva a la cual el sujeto puede acceder. No obstante, si dentro de una comunidad epistémica dos individuos observan de forma diferente el mismo objeto y comparten marcos conceptuales (mas nunca exactamente iguales, dado que no son la misma persona con la misma experiencia y ordenamiento sensible), la pluralidad interpretativa de la observación se impone.

De acuerdo con esto, algunos observan a la "anciana" pero no a la "joven" (o viceversa), y ello se comprendería por la carga teórica personal que ordenó los datos de la experiencia sensible de forma tal que se observa a una o a otra, ambas o a ninguna; y esto parece ser independiente del hecho innegable de que sólo se tenían esas cuatro opciones.

Veamos: observo a una "joven" o a una "anciana" empero, y de acuerdo con el tenor de arriba, diría que también observo a una joven o anciana, respectivamente, porque, de hecho, "se parece al original". No puedo observar a un hombre (masculino) porque el objeto no se corresponde con la "imagen original" de un hombre. O en un sentido más fuerte: "ese objeto no representa a un hombre porque así no son los hombres. Así se ven las mujeres jóvenes o viejas (pero ¿así son?)”. De esta forma, admito una verdad por correspondencia que es independiente de mi carga teórica e historicidad implicando el conocimiento necesario: observo 'mujer joven' o 'mujer anciana' porque las líneas ahí representadas evocan lo que, en el registro de mi experiencia, es una 'mujer'.

Lo anterior no es convincente. No parece evidente que el individuo en realidad observe y moldee según los datos de su experiencia hacia ese conjunto de líneas, sino que parece que ve lo que se espera bajo la consigna de un contexto común. Es decir, que puedo entender que dentro de mi contexto, algunos o muchos observen así a una mujer anciana de facto, no obstante, no es lo que yo (u otros) observo.

Una de las principales influencias para Hanson es Ludwig Wittgenstein, quien le antecede en el planteamiento de la pluralidad interpretativa de la observación por la carga teórica. En sus Investigaciones 
filosóficas, Wittgenstein analiza imágenes que sujeta a la posibilidad y diversidad interpretativa, y algunas de ellas son, precisamente, figuras de perspectivas reversibles como la de pato/conejo.

Hay ciertas cosas que caen tanto bajo el concepto de 'conejo figurativo' como bajo el de 'pato figurativo'. Y una cosa así es una figura, un dibujo. Pero la impresión no es a la vez la de un pato figurativo y la de un conejo figurativo. "Lo que veo realmente tiene que ser lo que se produce en mí por el efecto del objeto sobre mí." Lo que se produce en mí es entonces una especie de copia, algo que uno mismo puede contemplar a su vez, que uno puede tener ante sí: casi algo así como una materialización (Wittgenstein 2003: 459) (figura 2).

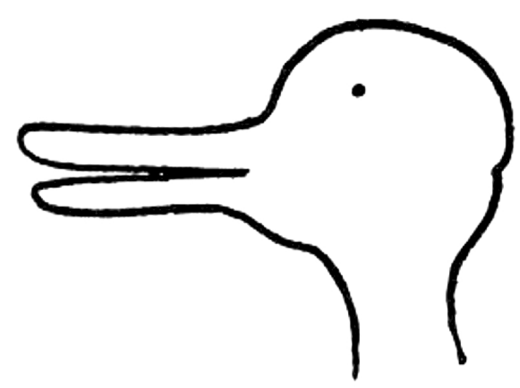

Figura 2.

El argumento permite discutir otras cuestiones. Si la imagen es el objeto y la impresión que el sujeto tiene de él no es, supuestamente, a la vez la de un pato figurativo y la de un conejo figurativo sino la copia del mismo, se afirma la dicotomía sujeto/objeto, la verdad por correspondencia y el conocimiento. Se presume la existencia de una realidad y el acceso a ella por parte del sujeto, toda vez que un dibujo puede ser la copia fiel de la misma, como lo es, precisamente, "un dibujo de conejo que se parece al conejo original".

Si primero se ve la imagen y luego se produce en el sujeto el efecto del objeto en una especie de copia como si se tratase de una fiel materialización, 1) el objeto es independiente del sujeto y por tanto, puede conocerse; 2) la relación entre el sujeto y el objeto es real, inmediata, sin afecciones ni condicionamientos; 3) la verdad por correspondencia es una cuestión de hecho. Siendo así, el condicionamiento teórico e 
histórico del observador no afectan a la observación, ya que el objeto en sí es externo al observador, posee características propias y el sujeto puede acceder a ellas sin condicionamientos externos que moldeen de forma diferente, impredecible y singular los datos de su experiencia. La observación o interpretación estarían al margen de la historicidad y de los marcos conceptuales del individuo. Pero Hanson señala lo contrario.

No está claro cómo un diseño condicionado ilustra la pluralidad interpretativa de la observación ni cómo la dirección teórica es un condicionante necesario y suficiente para el surgimiento de cierto tipo de interpretación. Sí muestra, por otro lado, cómo la carga teórica nos constriñe (reconocemos cierta idea de "joven" y de "anciano" que nos ha sido enseñada), pero no es aceptable el supuesto de que todos observen exactamente de la misma manera a una "mujer joven" o "anciana", la "juventud" o la "vejez", pues se estaría negando que, pese a reconocer a un elemento común, cada individuo observa de forma singular.

De reconocer que ese elemento se parece a la forma en la que algunos individuos dentro de un contexto, común o no, observan (y han convencionalizado) a una "mujer joven" o a una "mujer anciana", no se sigue que todos los miembros observan lo mismo en ese conjunto de líneas. Es decir, se puede reconocer como una de las formas en las que se reconoce (en espacio-tiempo) a la "mujer joven" o a la "mujer anciana", pero no porque de facto así se les esté observando, o no porque de hecho así sean. Por ejemplo, puedo reconocer que en muchos lugares de Oriente la vaca sea un animal sagrado pero, por más que yo lo observo, sólo interpreto un buen vaso de leche, un filete o una rodaja de queso. Puedo reconocer perfectamente lo que implica que la vaca sea un ser sagrado. Esto apunta a que el marco teórico respecto a la vaca sagrada no entra en mi observación/interpretación de ella, pese a que puedo entenderlo. No lo observo/interpreto pero lo entiendo, aunque existan quienes no lograrían entender ese marco teórico de sacralidad.

Existen diferentes interpretaciones de lo que ven, en común, todos los observadores. Las reacciones de la retina ante la figura $\mathrm{I}^{6}$ son virtualmente idénticas; también lo son nuestros datos sensoriales visuales, ya

6 La aludida figura I representa un cubo. 
que nuestros dibujos de lo que vemos tendrán el mismo contenido. No existen, pues, diferencias en la visión. Estas diferencias deben corresponder, por consiguiente, a las interpretaciones que se dan de lo que se ve (Hanson 2010: 224).

No negamos que la teoría implique cierto constreñimiento para la observación; lo que discutimos es que sea una condición necesaria y suficiente para el caso. ¿Por qué razón Hanson no utilizó "cosas del mundo libre" que no estuviesen diseñadas, como las nubes? Encontrarle formas a las nubes es una práctica que muchos seres humanos han tenido a lo largo de la historia y se trata de una experiencia netamente personal. Puede parecer un ejemplo sencillo, pero merece la pena reflexionarlo. Las formas que se le dan a las nubes refleja algo singular de cada individuo, su contexto e historia, su experiencia sensorial en sí, su carga teórica. Las nubes no tienen una forma, no están diseñadas, pero muchos de nosotros siempre les hemos encontrado alguna. Lo interesante es que dicha forma apenas dura unos instantes para luego convertirse en algo más, mostrándose así como formas insustanciales, impermanentes y cambiantes: no es igual lo que observamos de niños a lo que observamos ahora; tampoco lo es lo que observamos en un día triste o feliz. Básicamente, las formas de las nubes se han ido modificando con el paso del tiempo, al igual que nosotros y el mundo.

Y aún aquí la dirección teórica no es suficiente. Sucede algunas veces que escuchamos la descripción teórica sobre "cierta nube que es idéntica a algún X", un X que teóricamente reconocemos cultural, histórica y contextualmente pero que, legítimamente, no observamos (o viceversa, para el caso de ser uno quien lo advierte y lo describe). Más aún, no sólo no lo observamos sino que, en cambio, observamos una cierta Y en la misma nube y decimos: "sé a qué te refieres con $\mathrm{X}$, pero yo no lo observo, yo observo una $Y^{\prime}$.

Esta práctica no parece encontrar constreñimientos suficientes y necesarios. ¿Por qué? Mirar "formas en las nubes" refleja la vasta pluralidad ontoepistemológica de la observación. Observarlas y prestar atención a lo que sucede en el proceso y cómo suceden las interpretaciones contingentes e impermanentes, puede ser un buen experimento. Ahora veamos lo siguiente: 
Yo veo un oso trepando por la cara posterior de un árbol. Cuando usted se da cuenta de esto, los elementos ¿adquieren "armonía”, coherencia, se organizan? Usted podría decir con Wittgenstein: "no ha cambiado y, sin embargo, lo veo de otra forma...” Entonces, ¿no es verdad que tiene “una ‘organización’ muy particular’? (Hanson 2010: 229) (figura 3).
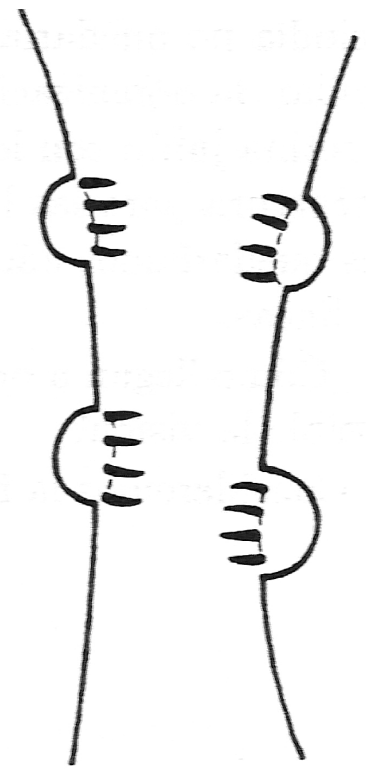

Figura 3.

Es aceptable considerar que la organización es parte de la interpretación de los datos sensibles de la experiencia, pero cuando dos individuos dentro de un contexto común (que no significa "contexto idéntico") dirigen el globo ocular hacia el mismo objeto y alguien enuncia "yo veo un oso trepando por la cara posterior de un árbol", uno de éstos, o ambos, permanece sin organizar la misma armonía. Esto no significa que no reconozca el concepto "oso", "trepar", "árbol”, "posterior", etc.; lo que significa es que observa otra ontología del objeto y que, por lo tanto, organiza de un modo distinto los datos de su experiencia sensible. En este sentido, la dirección teórica y el reconocimiento de la misma no es una condición de necesidad para cierto tipo de observación.

De acuerdo con lo anterior, podemos encontrar un vínculo. Tanto Wittgenstein como Hanson sugieren que la interpretación dependerá de 
aquello que ya se conoce, esto es, que no podrías observar el conejo si éste no se encuentra en el registro de tu experiencia. Suponen que si lo está y el objeto se "parece al original”, entonces observarás al "conejo"; pero esto no parece ser una condición suficiente y necesaria, por ejemplo: "reconozco que el canibalismo ha existido y existe", digamos que "lo sé", por lo cual de alguna manera singular se encuentra en el registro de mi experiencia, pero no observo a un ser humano como alimento.

Por otro lado, advertimos otra cuestión: la manipulación del objeto. La imagen pájaro/antílope ilustra bien lo que queremos señalar. Hanson explica cómo la teoría dirige la observación cuando supone que observamos "pájaros" en la primera imagen y luego de la dirección teórica, comenzamos a observar a los "antílopes". Es posible que algunos de los lectores que observaron dicha figura y que comparten una carga teórica más o menos común, hayan observado "pájaros" la primera vez... Después, al atender la explicación teórica del autor, volvió a mirar la imagen y comenzó a observar los "antílopes". ¿Por qué sucedió? La respuesta resulta curiosa: los "antílopes" que fueron observados aparecieron porque, de hecho, la imagen cambió a conveniencia para que lo hicieran. O dicho de otro modo, el objeto de observación cambió.

Compárense ambas imágenes. Podrá notar, luego, que la posición de las líneas que recreaban una imagen al comienzo (la que algunos reconocerían como "pájaros") se modificó en relación con la segunda imagen (que algunos reconocerían como "antílopes"). Esto significa que no se trata de la misma imagen, no se trata del mismo objeto de observación.

Cabe agregar que el autor mismo anota: "Incluso se podría aducir que la figura 5 [la de los antílopes] no es similar a la figura 6 [la de los pájaros], aunque las dos sean congruentes" (Hanson 2010: 231). Mas ésta no es una cuestión trivial. Prestemos atención a la figura que en cada imagen se encuentra en la esquina inferior derecha y que parece ser exactamente la misma (pero no lo es). ${ }^{7}$ Supuestamente, con ésta se

\footnotetext{
Obsérvense con cuidado las dos imágenes clave, sobre todo préstese atención a la variación de la forma del ojo así como al cambio de su posición, detalles que impactan considerablemente la totalidad de la imagen haciéndolas dos diferentes: una adquiere mayor congruencia con sus compañeros pájaros, y la otra, adquiere mayor congruencia con sus compañeros antílopes. Pero esto no pasa por el contexto
} 


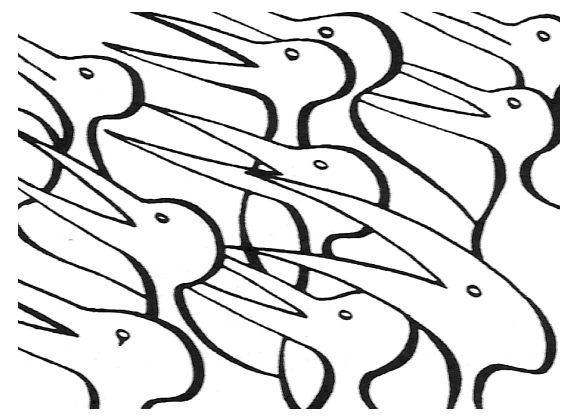

Figura 4.

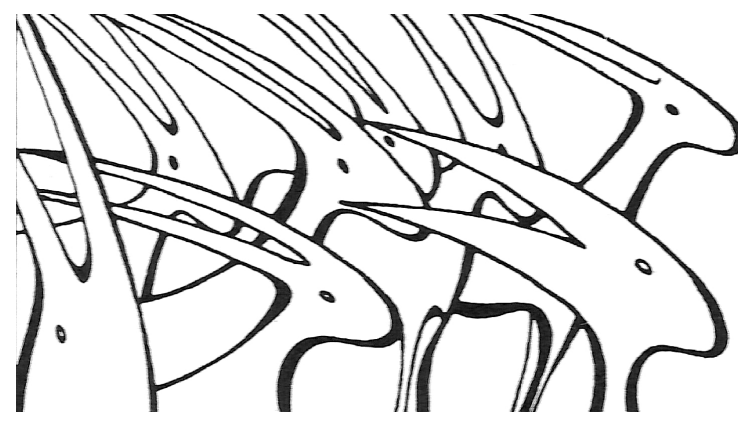

Figura 5 .

evidencia la clave al asumir que se trata del mismo objeto de observación en contextos distintos. ${ }^{8}$

Si hubo la intención de cambiar la figura de tal suerte que con un mínimo cambio y apoyándose de la dirección teórica "aparezcan" otros objetos, se advierte otra importante contradicción. Este ejemplo sería válido si y sólo si los globos oculares estuvieran dirigidos hacia el mismo objeto de observación, y no es el caso. Al contrario, el cambio en la observación ocurrió porque se utilizó, de facto, otro objeto de observación, no por la dirección teórica y el contexto. No se trata de que haya una supuesta "congruencia", cuestión que también es discutible, sino de

de la imagen, sino porque como objeto ha sido modificado intencionalmente. Asimismo podrían advertirse otros detalles, como el tamaño de la figura, el largo y el grosor del cuello, también su forma y la distancia entre el ojo y la comisura de la boca: lo puntiagudo de un hocico y lo redondeado de una cabeza.

8 Véase Hanson 2010: 230 y 231. 
que se utilizaron dos objetos de observación diferentes en dos contextos de observación distintos. Siendo así, ¿se trata de diseñar y modificar el objeto a conveniencia para fomentar determinadas situaciones de observación?

Todo modelo didáctico tiene sus limitaciones y está sujeto a resultados impredecibles. No obstante, esto no justifica el cambio de los fundamentos. Una de las premisas principales planteadas por Hanson, y que fundamenta el argumento en favor de la pluralidad interpretativa de la observación, es aquella donde el globo ocular, en condiciones normales respecto a su funcionamiento, se dirije hacia el mismo objeto. Al no cumplirse en el presente caso, nos recuerda otra problemática: hacer modificaciones ad hoc del objeto y de la teoría para que se correspondan recíprocamente.

En efecto, cuando Hanson procede a hacer estos curiosos cambios, parece ser fiel a una tradición cientificista, donde las modificaciones ad hoc, tanto de la teoría como de las explicaciones y la evidencia empírica, han sido una práctica que pretende aludir a una correspondencia recíproca, problema que ya ha sido advertido por otros importantes filósofos de la ciencia como I. Lákatos y P. Feyerabend. La sutileza de un engaño explicativo para sostener un argumento nos recuerda aquello a lo que Feyerabend (en 1975) se refería con la irracionalidad de la ciencia así como lo fácil que es convencer a la gente de una forma irracional, ${ }^{9}$ donde el método (y las reglas) de la ciencia admite como válidos y necesarios en su desarrollo histórico las modificaciones e hipótesis ad hoc, las cláusulas ceteris paribus y otros artilugios retóricos.

Incluso cuando todo modelo didáctico tenga sus limitaciones no hay excusa para ignorar las premisas fundamentales que dan sustento al argumento, de otro modo, el planteamiento queda invalidado o comienza a debilitarse. Arriba hemos sugerido otras alternativas, como la dirección del globo ocular hacia objetos de observación como las nubes, pero también existen otras ideas. En Lecciones sobre el pragmatismo, Charles Sanders Peirce utiliza un garabato o, como él mismo refiere, una "línea serpentina" para señalar una cuestión que encuentra puntos en común con la teoría hansoniana:

9 Cf. Feyerabend 2010 y 2011. 
Les mostraré una figura que recuerdo que dibujó mi padre [Benjamín Peirce] en una de sus lecciones. No recuerdo lo que quería explicar con ella; pero no alcanzo a imaginar qué otra cosa habría podido ser [...] He aquí la figura (aun cuando no sé trazarla con tanta destreza como él), consiste en una línea serpentina. Pero una vez trazada por completo, semeja una pared de piedra. Lo esencial es que hay dos maneras de concebir el asunto. Ambas, les ruego que reparen en ello, son maneras generales de clasificar la línea, clases generales bajo las cuales se subsume la línea. Mas el hecho mismo de la decidida preferencia de nuestra percepción por un modo de clasificar el percepto muestra que esta clasificación está contenida en el juicio perceptual (Peirce 1978: 220-221) (figura 6).

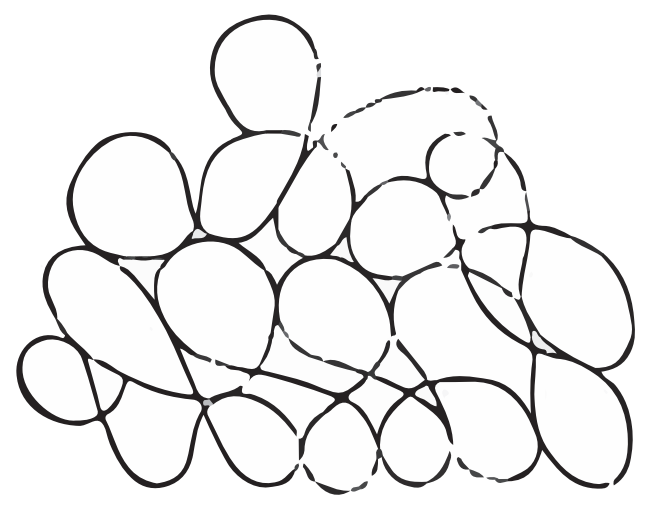

Figura 6.

Resaltemos algunos puntos. El primero se vincula directamente con la idea hansoniana de la pluralidad interpretativa de la observación. Peirce explica que una vez trazada la "línea serpentina" por completo, lo que "ahí se ve semeja una pared"; pero el enunciado merece precisión, pues, "lo que ahí se ve a Peirce le parece que semeja una pared". El segundo se advierte cuando el autor señala que existen dos maneras de concebir la imagen, esencialmente porque el tipo de clasificación que prefiera la percepción dependerá del juicio personal: se ve una pared o una línea serpentina. Pero, ¿se ve una pared o una línea serpentina? Persisten los problemas.

Aunque Peirce admite que la clasificación que efectúa la percepción dependerá del juicio personal, el asunto es que éste implica en sí mismo la pluralidad, y no obstante él escribe: "lo que ahí se ve semeja una pa- 
red". El caso es que la imagen y el trato que el autor le da siguen entrando en el ámbito de la admisión de la relación sujeto/objeto, la verdad por correspondencia y el conocimiento necesario. El punto interesante está en lo que Peirce determina como "se asemeja a...". Desde su perspectiva, la semejanza permite establecer relaciones de sentido que no necesariamente implican la existencia del objeto, porque el sentido mismo se construye en razón de los vínculos convencionales que hay entre sistemas de lenguaje, esquemas, teorías y creencias: si la "estructura del sujeto" es capaz de moldear los datos de la experiencia sensible sólo a través de éstos, la pluralidad ontoepistemológica se presenta como algo necesario.

Grosso modo, se puede anotar críticamente que el uso de un diseño condiciona y limita la pluralidad interpretativa de la observación y contradice la intención de mostrar sus implicaciones ontoepistemológicas. Además, de admitir que compartir marcos conceptuales constriñe en alguna medida las posibilidades interpretativas de la observación, no se sigue una condición necesaria para una observación limitada y predecible.

Éste no es un descubrimiento reciente sino la base fundamental de la propuesta hansoniana. El análisis de la relación recíproca entre los recursos metodológicos que utiliza Hanson y su propuesta teórica, revela contradicciones. Esto porque al mismo tiempo en que se defiende una pluralidad, se nos pone a prueba aludiendo una predecibilidad; y si esto es así, es porque, pese a todo, se admite la relación sujeto-objeto, la verdad por correspondencia, la necesidad de las modificaciones ad hoc y el conocimiento necesario: primero veo, luego interpreto. Y esto ocurrió por el manejo de figuras de perspectivas reversibles.

Es posible, entonces, que el mismo Hanson no haya escapado de la tradición racionalista anglosajona al no cuestionar la temporalidad del ser, la impermanencia, y vislumbrar las implicaciones de la pluralidad ontológica y epistemológica de la observación. Empero, cabe señalar que Hanson perteneció a una tradición que se remonta a 1958, cuando todavía se abanderaba la posición monista y una verdad por correspondencia biunívoca: una y sólo una interpretación de la realidad en su relación inmediata entre sujeto y objeto, lo que se pensaba llevaría al conocimiento necesario. Sin embargo, la propuesta de Hanson es inne- 
gablemente revolucionaria al descubrir la naturaleza histórica y plural de la observación, por lo que su obra no deja de ser un hito en la filosofía de la ciencia y sobre todo en la hermenéutica.

\section{Epistemología en Hanson: sobre el concepto analítico del lenguaje y sus límites hermenéuticos}

En otra dirección, delimita la noción "lenguaje" como un elemento que actúa sobre la visión, pues permite la construcción de "observaciones significantes", es decir, observaciones con sentido que posibilitan la organización de los datos sensibles. El lenguaje está conformado por enunciados que hacen posible la organización subjetiva de los datos sensoriales y desde ahí, se constituye un "ver qué" en tanto elemento conectivo entre las afectaciones del mundo (externo) y el conocimiento previo.

La delimitación del concepto "lenguaje" trabajado por Hanson permite hacer dos lecturas de su propuesta. Por un lado, parece en principio sugerir una perspectiva hermenéutica, a la manera de Martín Heidegger o Hans-Georg Gadamer. Sin embargo, los alcances de este planteamiento quedan limitados por los atavíos de una tradición cientificista, que obligan a destacar el carácter analítico del lenguaje. Por eso, en otra dirección, el autor sostiene su noción de interpretación sobre la base de conceptos y relaciones que derivan de la tradición moderna y que aún fundamentan su planteamiento desde una posición epistemológica (y no ciertamente desde una ontología del lenguaje).

Para llegar a este punto, en el apartado anterior se buscó mostrar que el planteamiento hansoniano, argumentado desde la perspectiva de imágenes reversibles, resulta problemático puesto que la estrategia de utilizar estas imágenes no permite desarrollar una postura ontológico-hermenéutica, sino que parece un recurso retórico a través del cual el autor encuentra una solución plausible al dilema presentado. Las imágenes duales, pues, nos enfrentan a lecturas condicionadas y no alcanzan a mostrar la complejidad ontológica de un planteamiento encaminado hacia una pluralidad interpretativa. Ahora bien, en los apartados siguientes cuestionaremos, no ya la metodología, sino los conceptos utilizados 
para argumentar la noción hansoniana de interpretación y, en este sentido, valorar el alcance de dicha teoría para establecer una hermenéutica en la ciencia.

En razón de esta coyuntura problemática, en las líneas subsiguientes se buscará mostrar cómo los planteamientos de Hanson con respecto a los conceptos de lenguaje e interpretación resultan más próximos a una tradición epistemológica, de carácter semiótico-analítico. Finalmente, al perfilar esta caracterización del planteamiento interpretativo hansoniano, se buscará además poner a consideración del lector una crítica de dichos conceptos pero desde la "ontología del lenguaje" propuesta por Gadamer, con la intención de mostrar la distancia teórica entre una postura analítica del lenguaje y una hermenéutica.

\section{Fundamentos semióticos y epistemológicos}

En términos generales, la semiótica como disciplina teórica estudia los signos desde una perspectiva analítica: se parte del supuesto que considera al lenguaje como un sistema o esquema. Desde ahí se aceptaría que el lenguaje está constituido por unidades que pueden ser analizadas a partir de categorías y relaciones dicotómicas (y en Peirce tricotómicas) para abordar su forma y contenido. Sin embargo, de la diversidad de lenguajes que constituyen la realidad social expresiva, la semiótica reconoce la lengua como el lenguaje a través del cual los demás sistemas de signos adquieren significado.

Puede argumentarse que el planteamiento teórico de Hanson se cimenta sobre la base de una postura analítica. Al respecto, y para sostener esta afirmación, es importante hacer notar que el autor plantea dicotomías para describir los momentos de un proceso de interpretación que él mismo reconoce ocurre como una unidad, pues ambos (ver-qué/ver-cómo) "son elementos lógicamente distinguibles del lenguaje sobre la visión, según el concepto que nosotros tenemos de ésta" (Hanson 2010: 241).

La distinción que Hanson establece entre imagen y lenguaje (entendido este último como lenguaje verbal) tiene implícito el problema semiótico de la referencia: en ambas nociones se asume la referencia a un objeto específico, ya sea por "convención" o "copia" de propiedades, 
como contenido de las representaciones. En términos generales se parte de una cuestión epistemológica que nos lleva a postular la existencia de entidades u objetos, como referencias de los signos y desde la cual se pueden considerar problemas que se circunscriben a la discusión en torno a la pertinencia del realismo frente a una postura nominalista. En esta discusión, sintetizada por Ian Hacking ${ }^{10}$ en términos de filosofía de la ciencia, se busca establecer la naturaleza y contenido de las representaciones de un determinado conocimiento.

La postura de Hanson sugiere una lectura encaminada hacia este problema moderno en relación con el objeto de referencia. Por un lado, se presenta la posibilidad del realismo, de donde se siguen dos lecturas interesantes: se puede afirmar un realismo metafísico, en cuya base está el criterio de "verdad por correspondencia", lo cual implica aceptar que las representaciones están vinculadas con los objetos que refieren; o bien se apuesta por un "realismo de las entidades" dispuestas por el lenguaje mismo, y donde la existencia de entidades y objetos de referencia se justifica en razón de la evidente "manipulación" e "intervención" empírica del lenguaje sobre dichas entidades. Por otro lado, se puede sostener un grado de nominalismo donde las entidades teóricas y objetos de referencia sólo forman parte de un lenguaje específico (o metalenguaje), y sólo tienen existencia dentro del conjunto mismo de representaciones que componen la estructura de dicho lenguaje.

La consideración del objeto de referencia como significado de los signos implica dos supuestos determinantes. Primero, la posibilidad de que un mismo signo puede tener como significado la asociación de una sola representación mental y segundo, que el objeto de referencia implica una relación de "naturalidad", donde los atributos de la cosa están de algún modo representados en el signo. En ambos niveles, la relación del signo con su referencia-significado es problemática, porque supone que signo y objeto son entidades que existen por sí mismas de manera independiente de todo contexto social.

En esta dirección, para Hanson la función de la imagen es representar, mientras que la del lenguaje (verbal) es describir/relatar. Ambos componentes están enmarcados en supuestos de naturaleza semiótica,

10 Cf. Hacking 1996. 
pues mientras la imagen-representación alude a problemas de analogía entre objeto y representación, el lenguaje establece su valor significativo en razón de un carácter convencional. Sin duda, esto muestra una contundente continuidad con una visión analítico-estructural, que supone de manera problemática relaciones específicas de analogía y convención entre signos de diferente naturaleza.

La propuesta de Hanson muestra atisbos de apegarse más a una concepción epistemológica (semiótica-analítica), y no propiamente ontológica (hermenéutica); da preeminencia significativa al lenguaje verbal, de carácter analítico-racional, por encima de cualquier otro tipo de signo y, muy al estilo de la tradición moderna, supone que es por medio de la palabra que el hombre puede conocer. De ahí que dentro de la propuesta hansoniana no se considere el acto originario del lenguaje que se realiza en el "habla" (Heidegger) y en la "conversación" (Gadamer), en donde el lenguaje, lejos de considerarse un instrumento, es el "ser" que surge de la confrontación con el otro dentro de un "proceso de comprensión" carente de cualquier anticipación de sentido, pues es en la comprensión del uno con el otro que lenguaje como habla-conversación desvela su propia verdad.

Al aceptar la dicotomía entre representación/lenguaje, el planteamiento epistemológico de Hanson se circunscribe a la discusión filosófica en términos del conocimiento como representación. De hecho, la imagen como representación en Hanson refiere la idea de una representación interna proporcionada por Descartes y desarrollada en sentido trascendental por Kant. En el centro de esta discusión, la idea de una representación interna, como fundamento del conocimiento, derivó en el argumento empirista de Locke acerca de la explicación mecánica de las operaciones de la mente y la fundamentación de la pretensión de conocimiento.

De ahí que la división entre lenguaje/descripción e imagen/representación sea próxima a la distinción empirista: una postura que sostiene la representación como fundamento del conocimiento y, por ende, obliga a determinar el conocimiento desde la relación de la representación con el objeto. Por supuesto, en esta orientación el carácter a priori de la estructura representacional del sujeto se constituye en la condición de posibilidad para la determinación del objeto como parte del conocimiento. 


\section{Lenguaje, comprensión e interpretación}

En este sentido, uno de los factores que distancian la propuesta de Hanson de una auténtica propuesta hermenéutica es la falta del elemento de "intersubjetividad" en su planteamiento. Como hemos visto, la propuesta hansoniana tiene como fundamento el a priori kantiano, en donde la estructura del sujeto es la condición de posibilidad del conocimiento; sin embargo, no reconoce que el lenguaje tiene sentido y adquiere sentido en el uso entre los sujetos hablantes y que, en todo caso, es el factor de la intersubjetividad lo que permite establecer la comprensión de sentidos.

Desde su perspectiva, Hanson reconoce la noción de "contexto", y en este sentido la "tradición" como elementos implicados en la interpretación, pues en todo caso lo observado tiene sentido y es interpretado dentro de un contexto de conocimientos que influye sobre la visión. Asimismo afirma que la interpretación, en relación con un "ver que...", un ver de conocimiento, no está determinada por un criterio de verdad fijo, sino que acepta la posibilidad del carácter cambiante de la observación y el conocimiento, en donde la información acerca de lo observado puede cambiar en virtud de nuevas observaciones ("observaciones adicionales") que ofrecen perspectivas y contenidos diferentes del anterior.

El carácter cambiante de la visión-comprensión y la idea de contexto nos acercan a los planteamientos hermenéuticos acerca de la "impermanencia", "tradición" y "vivencia". Específicamente, en relación con Gadamer, la noción de "carga teórica” permite establecer un parangón, donde el planteamiento gadameriano, al igual que la noción de Hanson, afirma que la interpretación depende del contenido. Así pues, la "carga teórica" alude a un conocimiento previo, y en clave hermenéutica este concepto se asemeja a la "tradición", que en Gadamer permite el orden inicial a partir del cual surge el dinamismo de las nuevas interpretaciones ("expectativas").

Ambos, tradición y conocimiento previo, son de naturaleza eminentemente lingüística. A diferencia de Hanson, la postura hermenéutica entiende el lenguaje como ser, pues en la conversación con el otro surge un lenguaje que genera su propio sentido y tiene así su "propio espíritu”. La "lingüisticidad" en Gadamer surge del proceso de comprensión 
donde el lenguaje es el medio a través del cual se realiza el acuerdo entre los interlocutores y el consenso sobre la cosa, pues a través de la conversación se "desvela y deja aparecer algo que desde ese momento (la conversación misma) es" (Gadamer 1977: 463).

Para Gadamer la relación entre lenguaje y comprensión es dialéctica, en donde la comprensión y lo comprendido interactúan lingüísticamente, y desde ahí, surge el vínculo entre ser y lenguaje. Mientras que Hanson piensa el lenguaje como un momento cognitivo de la interpretación, para Gadamer es un horizonte donde el mundo se revela en su totalidad. Para el hermeneuta alemán, no hay modo en que los intérpretes anticipen algún sentido de este lenguaje originario, porque el sentido surge de la "fusión de horizontes" de cada intérprete. Así, la conversación alumbra su propia verdad.

\section{Hacia una justificación de la Hermenéutica en las Ciencias}

Por un lado, el análisis crítico respecto al uso de figuras de perspectivas reversibles que tienen como objetivo mostrar la pluralidad interpretativa de la observación dentro del texto de Hanson, permitió vislumbrar posibles e importantes contradicciones que se contraponen con el corazón del planteamiento hansoniano. El problema es que la defensa legítima de la pluralidad interpretativa de la observación se vincula, necesariamente, con la admisión de la pluralidad ontoepistemológica y no con el realismo.

Así, se mostró que un diseño, que por definición es fijo, condiciona y limita la pluralidad interpretativa de la observación. Y es que uno de los principales fundamentos del planteamiento de Hanson es "ver porque se interpreta", lo que en sí mismo arguye por la pluralidad interpretativa de la observación y la pluralidad de ontologías y epistemologías.

Por otro lado, se discutió que del hecho de compartir marcos conceptuales no se sigue una condición necesaria para un tipo de observación "dada", limitada y predecible. Esto, porque compartir marcos conceptuales y reconocer esta condición no significa que las observaciones sean exactamente iguales, por lo que las formas en las que el individuo observa y actúa en consecuencia, habrían de ser netamente singulares. 
Advertimos algunas prácticas curiosas que se relacionan con problemas que se siguen discutiendo en la actualidad por sus importantes implicaciones en la búsqueda del conocimiento y las prácticas científicas. Estas prácticas, como mencionamos, además de mantener el vínculo con la relación sujeto-objeto, la verdad por correspondencia y el conocimiento necesario, admiten modificaciones ad hoc del objeto y de la teoría para que se correspondan recíprocamente.

Cuando Hanson realiza este tipo de práctica parece ser fiel a una tradición cientificista, donde las modificaciones ad hoc pretenden crear una correspondencia recíproca. El engaño explicativo, casi imperceptible, se utilizó por el autor para sostener o dar fuerza a su argumento, lo cual funcionó fácilmente, pero también motivó la reflexión en torno a la ética de la ciencia (natural o social) y, en general, de las comunidades epistémicas.

Asimismo, notamos importantes e interesantes anotaciones en Peirce por sus evidentes implicaciones. Un "se asemeja a..." da lugar al establecimiento de relaciones de sentido que no implican de forma necesaria la existencia del objeto, sino que el sentido mismo es construido en virtud de los vínculos convencionales que hay entre sistemas de lenguaje, esquemas, teorías y creencias, lo que lo mantiene dentro del argumento en pro de una verdadera pluralidad ontoepistemológica.

Si bien no negamos que la obra hansonniana representa un hito revolucionario al advertir la naturaleza histórica y plural de la observación, analizar su metodología nos permitió encontrar problemáticas metodológicas que contradicen y oscurecen el corazón de su propuesta. Igualmente, hemos evidenciado que los signos significan, no en relación con su objeto de referencia, sino en virtud de un proceso de confrontación subjetiva.

Por ello, desde las dos perspectivas críticas desarrolladas en este artículo, se demuestran los límites de la postura interpretativa de Hanson al considerar el sentido de los signos en relación con el significado y la referencia. En esta dirección, sugerimos que la tónica de una postura hermenéutica a la manera de Gadamer permite extender el planteamiento hacia la necesidad y pertinencia de la interpretación y comprensión en la ciencia, pues aunque el lenguaje científico trabaja con representaciones lógicas (categorías), la naturaleza de este lenguaje reconoce que 
el elemento significativo del signo está depositado en la convención y el uso social.

Este rasgo de la significación, como convención y uso, permite distanciar el lenguaje científico de la noción analítica que define al lenguaje como sistema de representaciones (cuya significación está en relación con la designación de un objeto de referencia), y posibilita considerar al lenguaje y su estudio desde un punto de vista diferente, donde el carácter social del signo nos lleva a pensar al lenguaje como un espacio que constituye el mundo social-cultural. De ahí la necesidad de considerar el estudio hermenéutico: "esta visión vincula la existencia de fenómenos, cosas o acontecimientos que podemos connotar y referir con nuestro lenguaje y, a su vez, el lenguaje expresa las características del mundo histórico en que se vive" (Velasco 2012: 211).

A fin de cuentas, las Ciencias Naturales y las Ciencias Sociales, en tanto que están conformadas por sistemas de lenguajes, son susceptibles del estudio hermenéutico, pues, de acuerdo con Ambrosio Velasco, la Hermenéutica resulta en un modelo "comprensivo" que tiende hacia la interpretación de acontecimientos sociohistóricos. Pero es en ello donde recae su pertinencia para el estudio de la Ciencia: las representaciones científicas son, en todo caso, manifestaciones sociohistóricas cuyo sentido muestra un modo particular (social) de ver el mundo. Por supuesto, esto nos lleva a plantear una distinción importante, ya que "frente al modelo naturalista de las ciencias, que aspiran al descubrimiento de leyes para explicar y predecir los eventos, naturales o sociales, las ciencias de la cultura no se proponen explicar y predecir los acontecimientos sociales con base en leyes y teoría universales, sino que buscan comprender su significado específico por medio de interpretaciones" (Velasco 2012: 212).

Para argumentar esta distinción, resulta necesario referir las precisiones hechas por Dilthey, para quien la diferencia entre las Ciencias de la Naturaleza (Física, Química, etc.) y las Ciencias del Espíritu (Historia, Filosofía, Ciencias Sociales, etc.) se establece precisamente en el modo como se da su objeto y en el método que se sigue para su captación. En un sentido más amplio, el mundo físico que circunda al hombre le ofrece imágenes cambiantes, las cuales contienen las cualidades sensibles del objeto percibido; pero la variabilidad de las imágenes no sólo 
se debe a las cualidades propias del objeto sino a las modalidades como aparecen al sentido externo.

En su crítica al positivismo, Karl Popper también planteó que la comprensión es el objetivo de toda ciencia, no sólo de las ciencias sociales y las humanidades. Pues la comprensión no es un proceso psicológico individual, sino un proceso intersubjetivo de interpretación. Pero, si bien para Popper las interpretaciones son objetivas y por tanto independientes de los sujetos, estas interpretaciones "pueden ser usadas por sujetos diferentes a sus productores originales, constituyendo el punto de partida para nuevas interpretaciones de los acontecimientos" (Velasco 2012: 222)

Pese a su carácter determinista, Popper también reconoce el papel de la "tradición" en la ciencia, y desde ahí sostiene que en la historia de la ciencia (en general) cada sociedad llega a un cierto nivel de conocimiento: es decir, llega a un cierto conocimiento disponible para solucionar los problemas concretos de una determinada sociedad. En razón de esto, para este autor resulta imposible el conocimiento "innovador" sin remitir necesariamente a la tradición que lo sustenta. Y, en este tenor, se resalta de nueva cuenta el papel de la historia y el contexto social para el estudio del conocimiento científico.

\section{Bibliografía}

Dilthey, Wilhelm (1978). Introducción a las ciencias del espíritu. México, Fondo de Cultura Económica.

- (1986). Crítica de la razón histórica. Barcelona, Península.

FABRIS, Adriano (2001). El Giro Lingüístico: hermenéutica y análisis del lenguaje. Madrid, Akal.

Feyerabend, Paul (2004). Provocaciones filosóficas. Barcelona, Biblioteca Nueva.

- (2010). Tratado contra el método. Madrid, Tecnos.

Gadamer, Hans-Georg (1977). Verdad y método. Salamanca, Sígueme.

HACKING, Ian (1996). Representar e intervenir. México, Universidad Nacional Autónoma de México/Paidós.

Hanson, Norwood Russell (2010). Patrones de descubrimiento. Madrid, Alianza. 
KAnT, Immanuel (2007). Crítica de la razón pura. México, Taurus.

León y PÉrez Ransanz, Ana Rosa (2010). Filosofía de la ciencia: teoría y observación. México, Siglo XXI/Universidad Nacional Autónoma de México.

PeIRCE, Charles Sanders (1978). Lecciones sobre pragmatismo. Buenos Aires, Aguilar.

POPPER, Karl (1972). Conjeturas y refutaciones: el desarrollo del conocimiento científico. México, Paidós.

Putnam, Hilary (2012). Mente, lenguaje y realidad. México, Universidad Nacional Autónoma de México, Instituto de Investigaciones Filosóficas.

Velasco, Ambrosio (2012). Hermenéutica y ciencias sociales. México, Universidad Nacional Autónoma de México, Instituto de Investigaciones Filosóficas.

WitTGenstein, Ludwig (2003). Investigaciones filosóficas. México, Universidad Nacional Autónoma de México. 